\title{
Dynamic testing: determining the residual dynamic capacity of an axially strained tendon
}

\author{
G Knox New Concept Mining, South Africa
}

A Berghorst New Concept Mining, USA

\begin{abstract}
The specification of a tendon is stated as the capacity of the tendon in pristine condition on the day of delivery to the mine. A number of factors result in the degradation of the capacity of a tendon. Factors such as, but not limited to, installation quality, corrosion, and ground movement are all understood to reduce the residual capacity of a system. An understanding of the effects of the degradation of a tendon is important when determining the risk of an excavation. Rock support tendons are discretely tested quasi-statically (closure) or dynamically (seismicity) depending on the conditions expected with the mine environment. Although this testing is valuable, it is likely that a tendon subjected to rapid ground movement (seismicity) would first be subjected to some level of slow closure. This paper forms a basis for future work into determining the residual capacity of a tendon; the focus of this paper is to determine the residual dynamic capacity of an axially elongated tendon. Samples were axially elongated quasi-statically and fixed into place prior to being subjected to a single dynamic impulse (56 kJ), resulting in the rupture of the tendon, using the Dynamic Impact Tester from New Concept Mining. A trend of increasing ultimate dynamic load and total elongation (determined as the summation of the quasi-static and dynamic displacement) sustained prior to the rupturing of the tendon, was noted. However, the total energy absorbed by the tendon indicated the fact that the total energy of the tendon remained constant.
\end{abstract}

Keywords: dynamic testing, ground support, pre-elongated, squeezing ground, seismic event, rockbolt, PAR1 Resin Bolt, Dynamic Impact Tester, New Concept Mining

\section{Introduction}

In an effort to solve difficult ground support problems, many mines are using ground support that is designed to support ground that will move. In some cases, this movement can come in the form of squeezing ground, which slowly elongates the ground support in essentially a quasi-static type displacement condition ( $\mathrm{mm} /$ day). In other cases, this movement can be a sudden and rapid $(\mathrm{m} / \mathrm{s})$ as seen during a seismic event. Normally, ground support is qualified for each of these types of elongation conditions separately, with either quasi-static testing or dynamic testing performed on the ground support. In most cases, dynamic testing is performed on ground support that is in pristine condition; the ground support is in a state of zero static elongation at the time of testing. These separate testing methodologies make sense if a mine experiences only one of these types of ground movement. However, it is more likely that the ground support system will be subjected to rapid ground movement $(\mathrm{m} / \mathrm{s})$ after being subjected to quasi-static closure $(\mathrm{mm} /$ day). This means that ground support testing using a discrete testing methodology may not fully define the performance of the ground support; the effect of the slow ground closure on the residual dynamic capacity is unknown.

'Determining the demand and the capacity of a support system is problematic especially when rockbursting conditions are considered' (Stacey 2012). Due to the varied nature of underground conditions, both the demand and the capacity are time-dependent. Ground motion is one of the components of support system degradation that should be considered. A number of degrading factors are worth considering. Some of these are installation quality, corrosion, and mechanical damage as a result of blasting or equipment 
contact. A number of these factors were investigated by Hadjigeorgiou (2016), where a conceptual representation of the degradation of the ground support system was proposed (Figure 1).

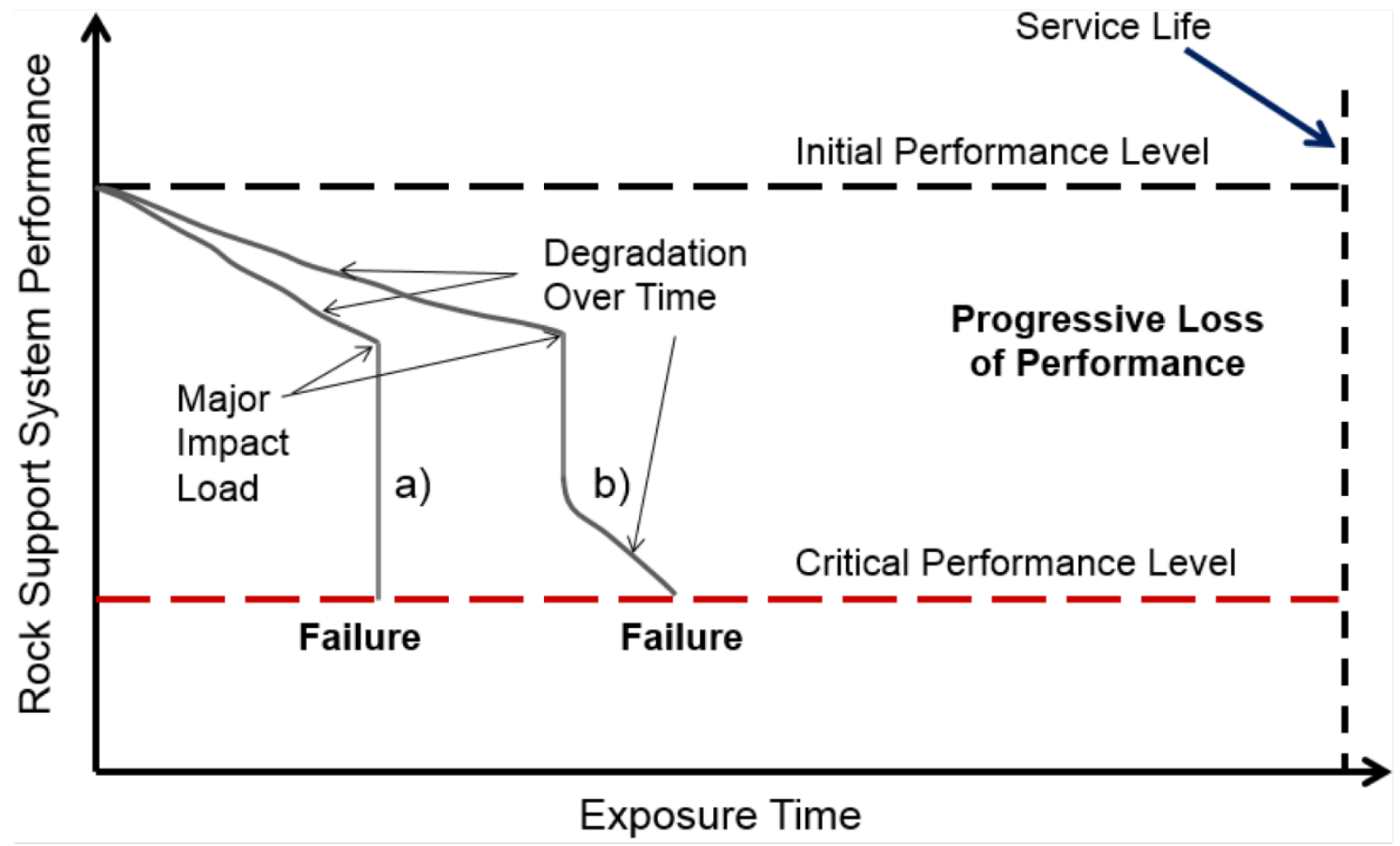

Figure 1 Degradation of a support system over time (Hadjigeorgiou 2016)

Ground motion can result in any combination of tensile, shear, bending and (in some cases) torsional strain of a tendon; however, current testing equipment limits the ability to test support systems dynamically under either tensile or shear elongation. As a result, this paper focuses on a purely axial elongation of the tendon. The degradation cycle 'a)' represented in Figure 1 was selected where a quasi-static elongation is represented by the initial degradation. The major impact is represented by a single dynamic impulse with a magnitude sufficient to cause the tendon to rupture. Therefore, the aim of this initial research was to begin to understand the residual dynamic capacity of a rockbolt quasi-statically axially elongated by a predetermined length.

\section{$2 \quad$ PAR1 Resin Bolt}

The PAR1 Resin Bolt (Figure 2) was selected for this investigation because this rockbolt has been extensively tested both quasi-statically and dynamically (Figure 3), and its performance is well understood. The PAR1 Resin Bolt consists of two paddle sets that perform the functions of mixing the resin and anchoring within in the cured resin. Energy is absorbed through elongation of the smooth steel portion; this can occur between the faceplate and the proximal paddle set and the proximal and distal paddle sets. The result is a highly repeatable performance under both quasi-static and dynamic elongation since this performance is defined by the properties of the steel (with less reliance on the quality of the resin). This is evident in the results depicted in Figure 3, which illustrates the energy absorption against the deformation of a number of different variants of PAR1 Resin Bolts testing in the Dynamic Impact Tester (DIT). The result of the additional load resulting from an increase in bar diameter ( $\varnothing 18 \mathrm{~mm}$ through to $\varnothing 25 \mathrm{~mm}$ ) was an increase in the energy absorbed. The results are not filtered by free length, with continuous tube, split tube and multi-split tube results and different paddle configurations presented; the trend is a linear increase in elongation and energy absorption proportional to the change in 'free length' of steel. As a result, the placement of the proximal paddle set alters the potential capacity of the bolt under different loading 
conditions. The variant of the PAR1 Resin Bolt selected for this research was the $\varnothing 20 \mathrm{~mm} 2.4 \mathrm{~m}$ version of the bolt with a standard paddle configuration (Figure 2).

Figure $2 \varnothing 20 \mathrm{~mm} 2.4 \mathrm{~m}$ PAR1 Resin Bolt

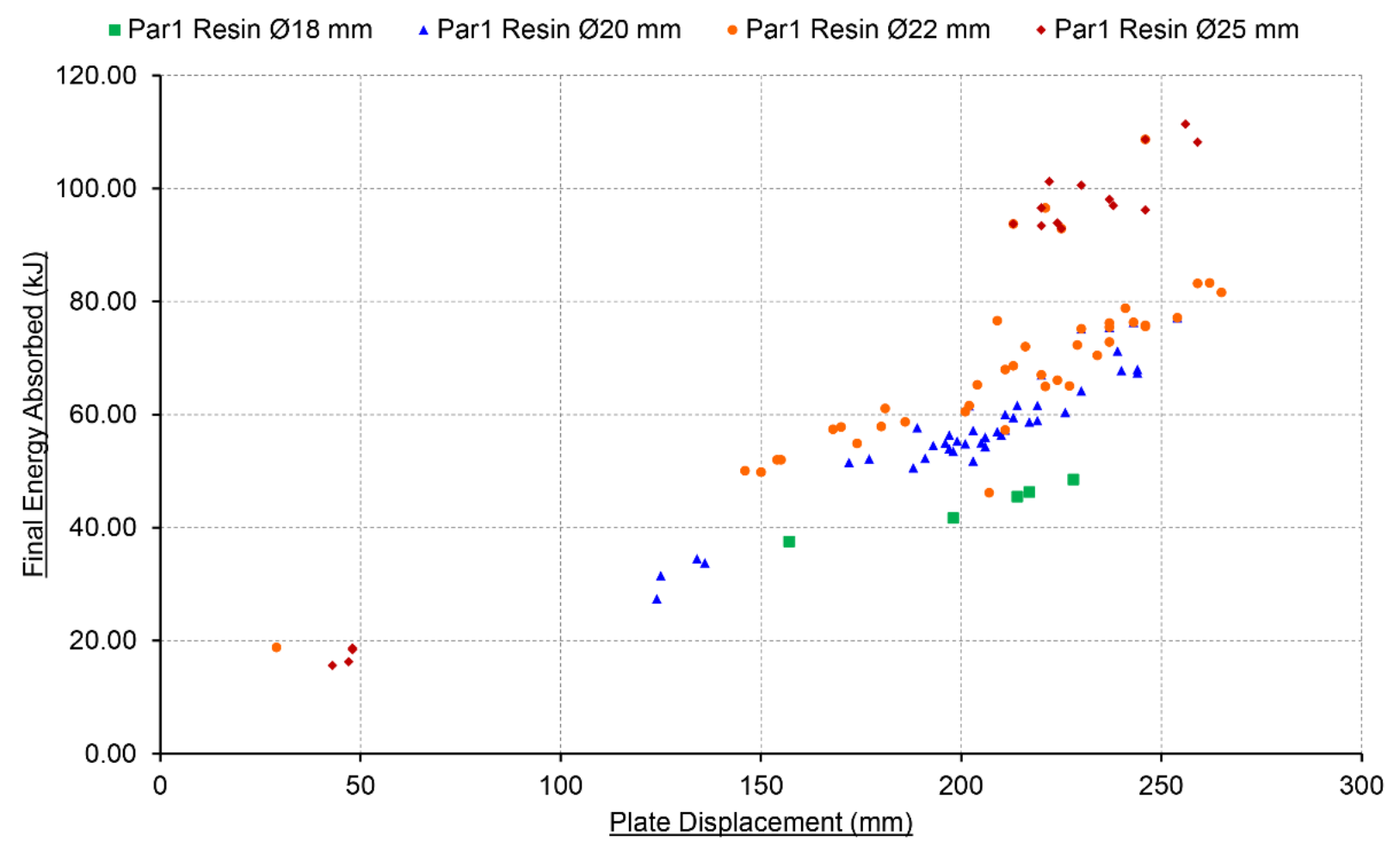

Figure 3 Summary of the dynamic testing of the variation of PAR1 Resin Bolts of different length, diameter and sample configuration methodology

\section{Sample preparation}

Due to the design of the New Concept Mining (NCM) DIT, it is not possible to quasi-statically elongate the bolt in the DIT. To perform this testing, a new sample tube arrangement (for housing the PAR1 Resin Bolt during this testing) and elongating frame was developed (Figure 6). The standard elongation of any tendon can be separated into two components: a linear elastic and a plastic component. This sample tube arrangement is designed to prevent the axial contraction of the tendon as a result of the elastic component of the elongation prior to dynamic testing. It is important to note that the quasi-static elongation placed on the tendon was not released and that the sample was dynamically tested with an impulse of energy of magnitude sufficient to rupture the tendon on the first impulse. As this was a preliminary investigation into understanding the effects of initial elongation on a support tendon prior to dynamically testing, 11 samples were prepared. The samples were split into four batches, the first three samples to be used as a benchmark for the dynamic capacity at zero initial elongation. The remaining batches of three samples were elongated to a displacement of $40 \mathrm{~mm}, 70 \mathrm{~mm}$ and, lastly, two samples at $100 \mathrm{~mm}$. These elongations were selected because they are significantly beyond the elastic elongation of the tendon (Figure 4). 


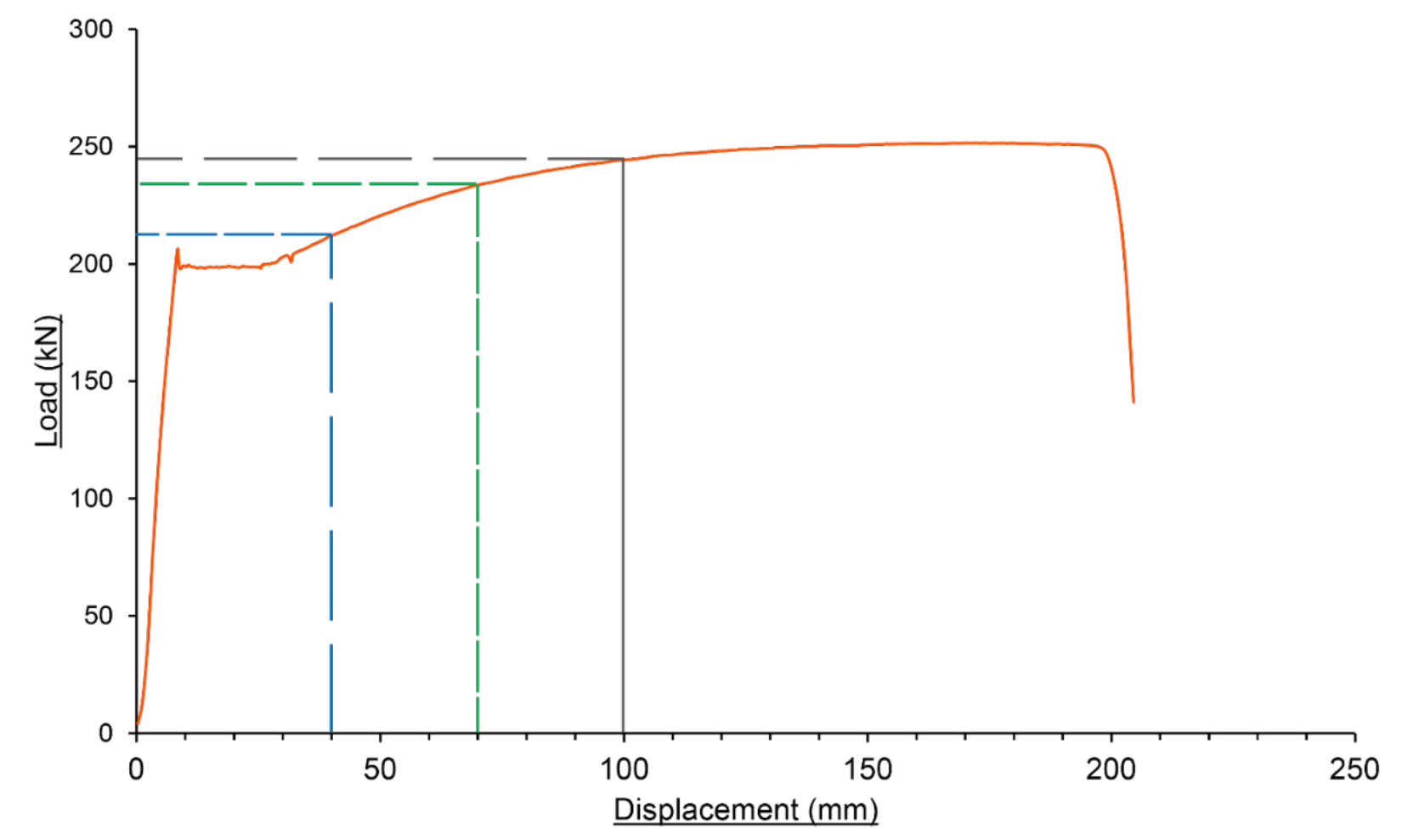

Figure 4 Quasi-static load-displacement curve for the PAR1 Resin Bolt

\subsection{Installation of the PAR1 Resin Bolt}

The sample tubes developed for this testing were configured for a split tube test (Li 2017). The split was located at approximately the midpoint between the proximal and distal anchor of the PAR1 Resin Bolt. The sample tube was threaded on either side of the split with a pair of couplers threaded to the sample tube to lock the sample tubes together across the split. The PAR1 Resin Bolt was installed using NCM's resin bolt installation machine (Figure 5). The machine allows the installation parameters to be set according to the resin supplier's specifications, with consistent thrust, rotation and hold parameters, as defined by Table 1. This practically eliminates the variability associated with a best-case installation.

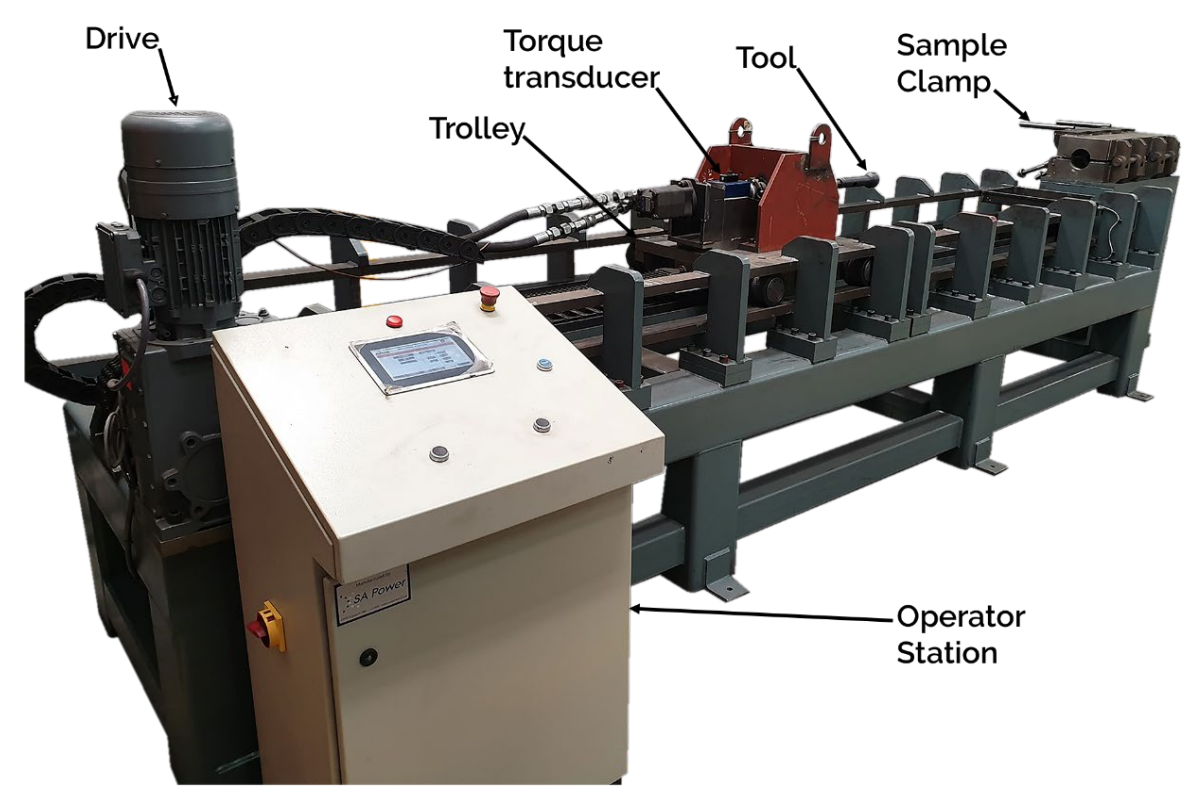

Figure 5 Equipment used to install the samples 
Table $1 \quad$ PAR1 Resin Bolt installation parameters

\begin{tabular}{ll}
\hline Parameter & Value \\
\hline Resin capsules & $1-$ fast, 5 - medium \\
Feed rate & $4.0 \mathrm{~m} / \mathrm{min}$ \\
Rate of & $300 \mathrm{rpm}$ \\
rotation & \\
Spin time & $10 \mathrm{sec}$ \\
Hold time & $45 \mathrm{sec}$ \\
\hline
\end{tabular}

\subsection{Elongation of the samples}

Once the PAR1 Resin Bolts were installed and the resin had cured for a minimum of 30 minutes, the samples were fitted into the quasi-static load frame (Figure 6). A loading coupler and drawbar were attached to the distal end of the sample tube, and the drawbar was passed through a hollow hydraulic cylinder. Prior to a quasi-static testing, the elongation coupler is rotated back (Figure 6); this allows the split between the tubes to open up when the hydraulic cylinder is pressurised. The loading is such that the sample is forced to elongate between the paddle sets. Once the predefined elongation was met using this method (Figure 6), the coupler was used to fix the position of the sample tubes prior to releasing the hydraulic pressure. The sample was then removed from the load frame, and the DIT receiver interface was attached to the distal end of the sample.

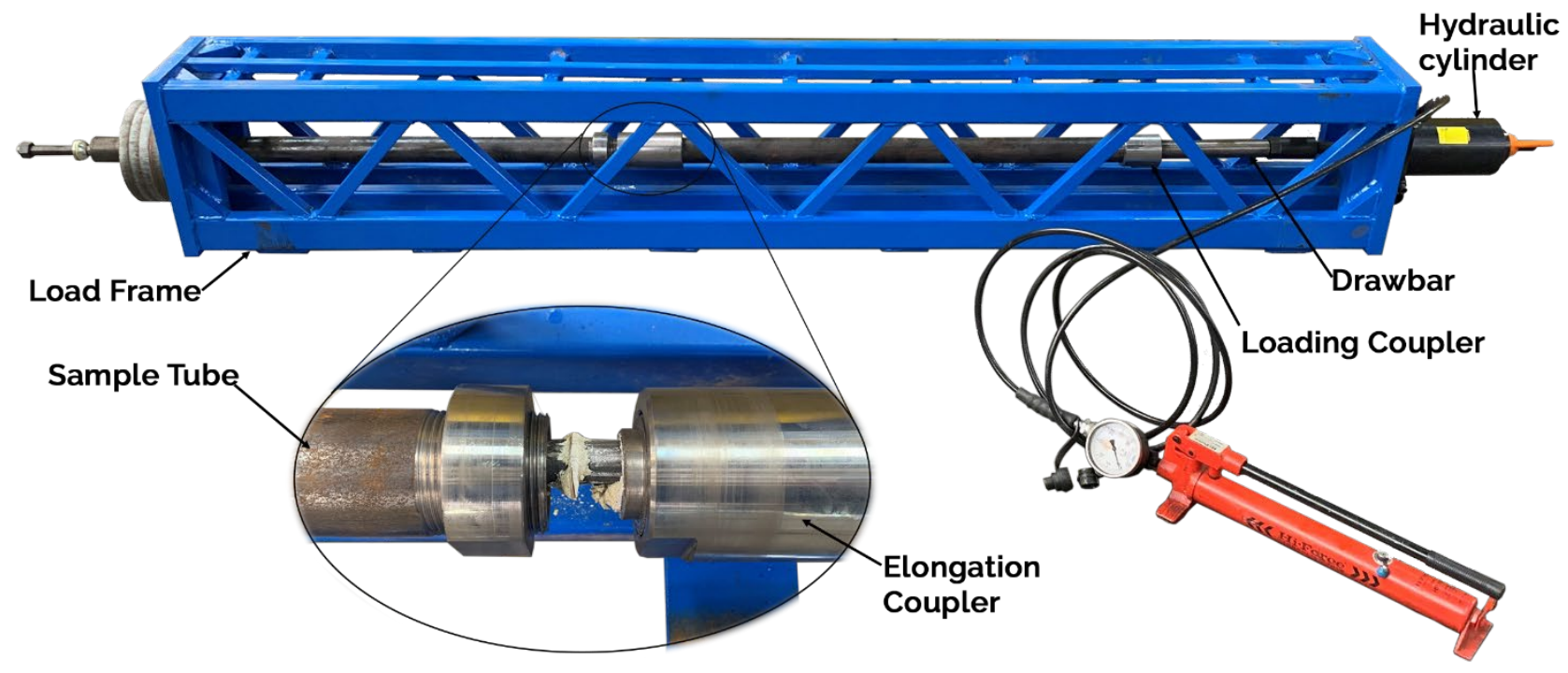

Figure 6 Equipment used to elongate the support tendons (patent pending)

\section{$4 \quad$ Dynamic testing}

Dynamic testing was conducted using NCM's DIT (Figure 7). The system uses a free-falling mass to generate an impulse of energy imparted to the sample through an impact. The machine was designed to meet the requirements of the now obsolete and currently under review ASTM D7401-08 (ASTM International 2008) specification. The machine as described by Knox \& Berghorst (2018) uses a known mass released from a known height to impart a predefined energy into the sample. During the impact, the loads and displacements are recorded at a rate of $10 \mathrm{kHz}$ the energy absorbed by the tendon prior to rupture, to be calculated. 


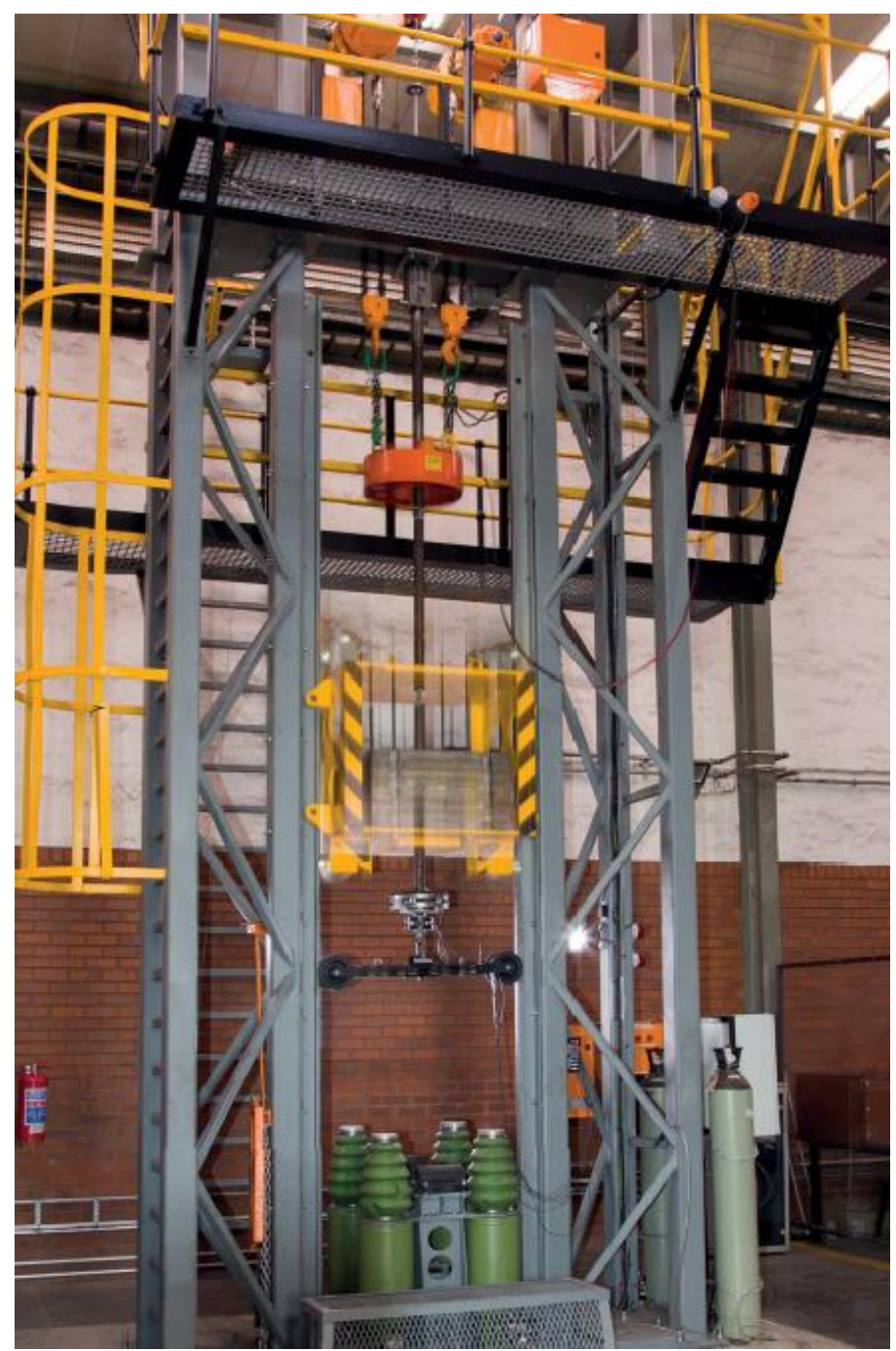

Figure 7 NCM's DIT during a test

Previous research conducted using the DIT determined that the magnitude of the input energy is inversely proportional to the total absorbed energy (Bosman et al. 2018). To mitigate the effect of multiple impacts, a single impulse of $56 \mathrm{~kJ}$, at an impact velocity of $5.9 \mathrm{~m} / \mathrm{s}$, was imparted onto the samples. This was a value previously established as sufficient to cause the $\varnothing 20 \mathrm{~mm}, 2.4 \mathrm{~m}$ PAR1 Resin Bolt to rupture when subjected to a single impulse.

Typically, a coupler is welded to the distal end of the sample prior to the attachment of the DIT receiver tube; however, there were concerns about using this welding process on an elongated bolt. From the previous testing conducted on the PAR1 Resin Bolt, the distal displacement is known to be less than $10 \mathrm{~mm}$ (Delport \& Knox 2018). Based on this, the decision was taken to forgo the distal displacement measurement and monitor the displacement after the quasi-static elongation and the dynamic testing.

\section{$5 \quad$ Results and interpretation}

A summary of the dynamic results from this research can be seen in Table 2 . In Figure 8 , these results are also represented graphically as a function of time and as a function of displacement offset by the initial quasi-static elongation. In the in situ environment, ground movement of the excavation is measurable, but the load and energy absorbed are not; however, the load is a function of the elongation of the tendon itself and hence the energy absorbed can be estimated. Therefore, the displacement, average impact load, and energy (the product of the displacement and average impact load) is used in this paper to compare the results. 
Table 2 Summary of the dynamic test results

\begin{tabular}{|c|c|c|c|c|c|c|c|c|}
\hline \multirow[b]{2}{*}{ Sample ref. } & \multicolumn{8}{|c|}{ Impact load (kN) } \\
\hline & $\begin{array}{l}\text { Quasi- } \\
\text { static } \\
\text { elongation } \\
{\left[d_{Q S}\right]} \\
(\mathrm{mm})\end{array}$ & $\begin{array}{l}\text { Plate } \\
\text { displ. } \\
{\left[d_{\text {DYN }}\right]} \\
(\mathrm{mm})\end{array}$ & $\begin{array}{l}\text { Offset } \\
\text { plate } \\
\text { displ. }^{1} \\
{\left[d_{\text {Total }}\right]} \\
(\mathrm{mm})\end{array}$ & Ultimate & Avg. & $\begin{array}{l}\text { Dynamic } \\
\text { absorbed } \\
\text { energy } \\
{\left[E_{\text {DYN }}\right](k J)}\end{array}$ & $\begin{array}{l}\text { Impact } \\
\text { duration } \\
\text { (ms) }\end{array}$ & $\begin{array}{l}\text { Time to } \\
\text { max. } \\
\text { load } \\
\text { (ms) }\end{array}$ \\
\hline 0_mm-S01 & 0 & 216 & 216 & 376 & 282 & 61 & 64.9 & 3.3 \\
\hline 0_mm-S02 & 0 & 220 & 220 & 288 & 269 & 58 & 70.2 & 48.7 \\
\hline 0_mm-S03 & 0 & 199 & 199 & 405 & 294 & 59 & 56.1 & 3.3 \\
\hline 40_mm-S01 & 40 & 182 & 222 & 417 & 287 & 52 & 49.2 & 3.0 \\
\hline 40_mm-S02 & 40 & 175 & 215 & 403 & 297 & 52 & 47.8 & 3.3 \\
\hline 40_mm-S03 & 40 & 184 & 224 & 324 & 281 & 52 & 49.9 & 4.1 \\
\hline 70_mm-S01 & 70 & 152 & 222 & 416 & 289 & 44 & 38.9 & 3.5 \\
\hline 70_mm-S02 & 70 & 158 & 228 & 415 & 290 & 46 & 40.8 & 3.3 \\
\hline 70_mm-S03 & 70 & 168 & 238 & 396 & 280 & 47 & 44.5 & 2.9 \\
\hline 100_mm-S01 & 100 & 145 & 245 & 433 & 310 & 45 & 37.4 & 3.4 \\
\hline 100_mm-S02 & 100 & 134 & 234 & 425 & 299 & 41 & 33.9 & 3.2 \\
\hline
\end{tabular}

${ }^{1} \mathrm{~d}_{\text {Total }}=$ das + dorn

二 $01 \mathrm{~mm}$ Avg. Load -70_mm Avg. Displ.

$40 \mathrm{~mm}$ Avg. Load
$\quad 0 \mathrm{~mm}$ Avg. Displ.

-10̄0_mm Avg. Displ.

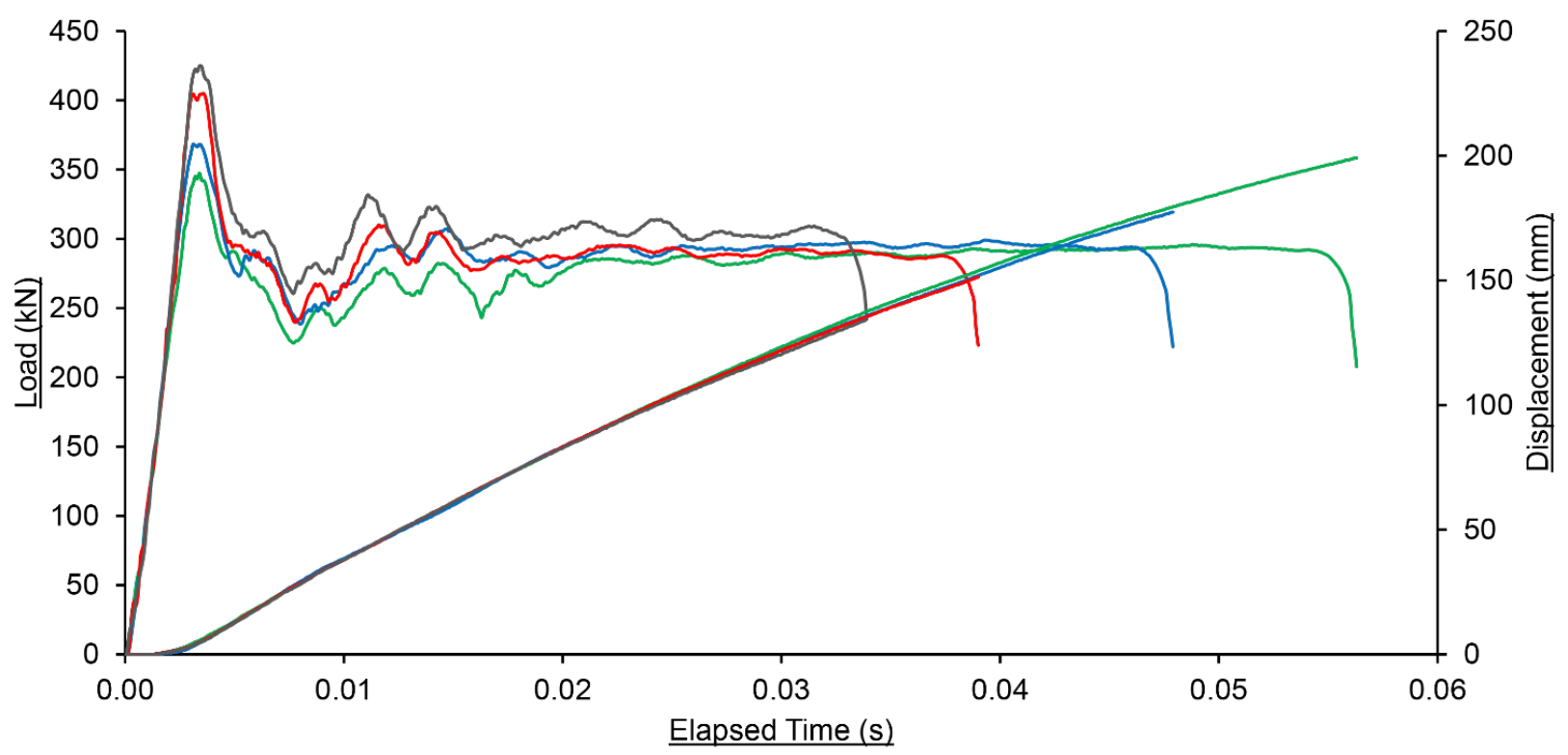

Figure 8 Average load and displacement over the impact period 


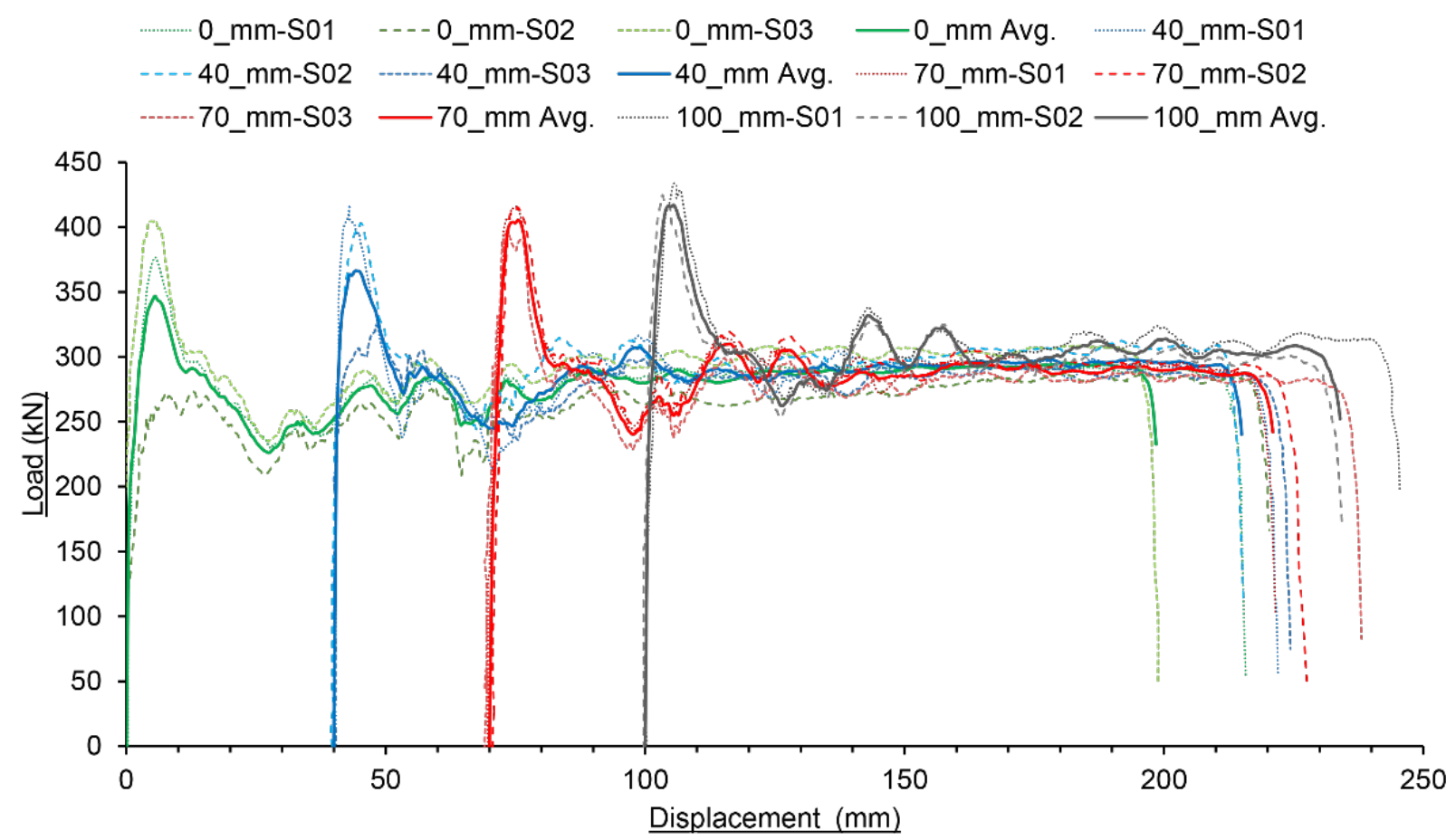

Figure 9 Average dynamic load-displacement curves, offset by the initial quasi-static elongation

In Figure 8, the average dynamic load and displacements are represented as a function of the elapsed time over the impact period. The profile of the load and displacement curves are consistent (showing the repeatability of the PAR1 Resin Bolt), with the ultimate impact load being reached within a range of 2.9 to $4.1 \mathrm{~ms}$, with the exception of ' 0 -mm-S02'. This suggests that the effect of strain hardening experienced during the quasi-static elongation does not have an effect on the initial stiffness of the sample. This is consistent with Knox et al.'s (2018) findings that the initial stiffness is related to the impact velocity. Rather, the effect of the strain hardening resulted in an increase in the ultimate peak loading as the quasi-static elongation was increased.

While there is a general trend towards an average increase in the average impact load, 282, 288, 287 and $305 \mathrm{kN}$, with an increase in the quasi-static elongation from 0 to $100 \mathrm{~mm}$, there is significant overlap in the average loads between the batches. This is clearly noted in Figure 9, suggesting that the increase in average load is, in fact, a function of the strain hardening effect, which continues during the dynamic loading.

As expected, when quasi-statically elongating the sample, a portion of the dynamic capacity of the tendon is consumed. This is echoed in the results displayed in Table 2, with a reduction in dynamically absorbed energy and displacement recorded. However, when the dynamic displacement is offset by the magnitude of the quasi-static elongation, a different trend is noted. The combination of a quasi-static and dynamic elongation results in an additional total displacement to rupture. The source of the additional displacement is currently unknown; however, repeatable relationships were noted between the ultimate loading and the displacement, suggesting it is not a result of the sample setup.

In short, trends noted in the results are represented in Figure 10. The quasi-static elongation resulted in a higher impact ultimate load during dynamic testing. A trend of strain hardening of the tendon noted throughout the sample set results in the load-displacement profile trending towards a similar load prior to rupture over the period for which the average impact load is calculated (peak impact load to maximum plate displacement). Finally, an increase is the total/offset elongation [ $d_{\text {Total }}$ was recorded. This is also represented in Figure 11 across the complete dataset. 


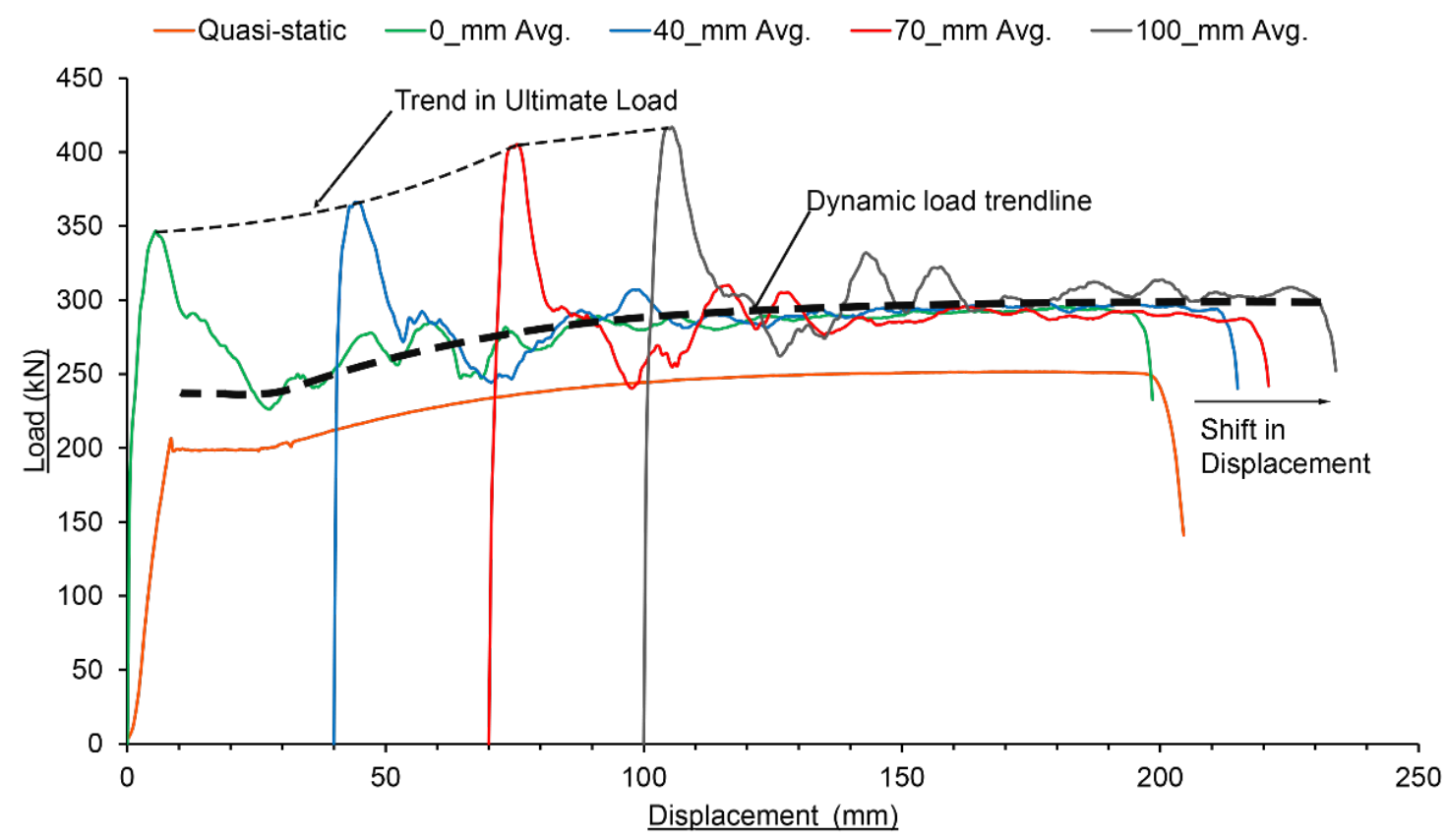

Figure 10 Graphical representation of the trends noted

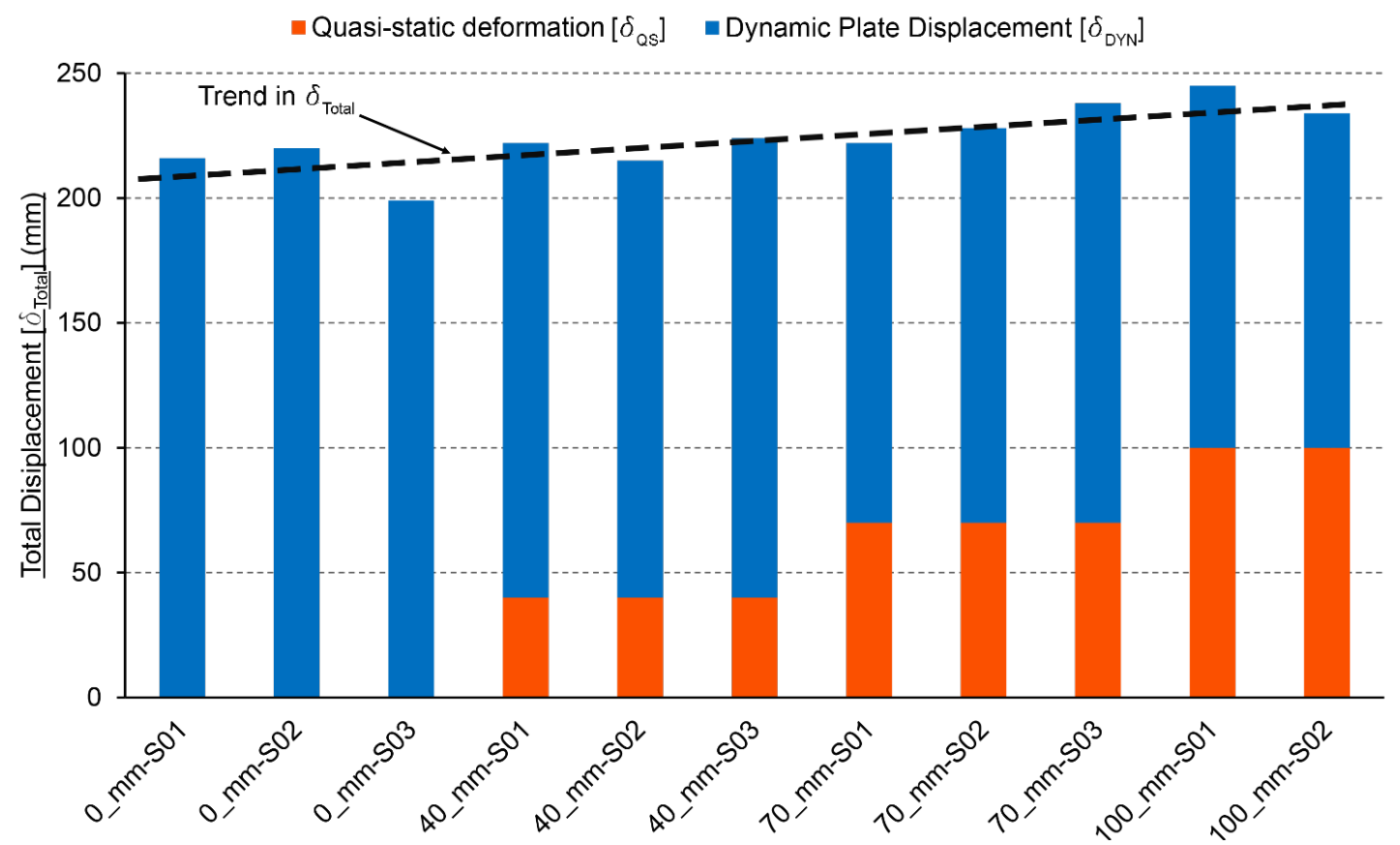

Figure 11 Average offset load-displacement curves offset by the initial quasi-static elongation

A component of the total energy capacity of the tendon is consumed during the quasi-static elongation of the samples. Therefore, it was expected that the calculated dynamic energy absorbed during the dynamic tests was going to decrease relative to an undeformed tendon, as seen in Table 3 . However, due to the stress-strain profile of the steel used in the PAR1 Resin Bolt, the reduction in residual dynamic capacity $\left[E_{D Y N}\right]$ is not proportional to the quasi-static elongation. However, what can be seen in Table 3 is that the relationship between the summations of the energy absorbed under quasi-static elongation $\left[E_{Q S}(x)\right]$ and the dynamically absorbed energy [ $\mathrm{E}_{\mathrm{DYN}}(\mathrm{x})$ ], the total energy, remained consistent across the batches. A minimal increase in the average total energy absorbed is noted in Table 3; however, when the total energy for the completed dataset is considered (Figure 12), it can be seen that, with the exception of the '100_mm' sample set, the difference is negligible when considering the variance within each batch. 
Table 3 Comparison between the energy sources

\begin{tabular}{llll}
\hline $\begin{array}{l}\text { Quasi-static } \\
\text { elongation } \\
\text { [das] }(\mathbf{m m})\end{array}$ & $\begin{array}{l}\text { Absorbed QS } \\
\text { capacity }\left[\mathrm{E}_{\mathrm{QS}}(\mathbf{x})\right] \\
(\mathbf{k J})\end{array}$ & $\begin{array}{l}\text { Residual dynamic } \\
\text { capacity }\left[\mathrm{E}_{\mathrm{DYN}}(\mathbf{x})\right] \\
(\mathbf{k J})\end{array}$ & $\begin{array}{l}\text { Total energy absorbed } \\
{\left[\mathrm{E}_{\mathrm{DYN}}(\mathbf{x})+\mathrm{E}_{\mathrm{QS}}(\mathbf{x})\right]} \\
(\mathbf{k J})\end{array}$ \\
\hline 0 & 0.0 & 59.1 & 59.1 \\
40 & 7.2 & 52.2 & 59.4 \\
70 & 13.9 & 45.8 & 59.7 \\
100 & 21.1 & 42.8 & 63.9 \\
\hline
\end{tabular}

- Quasi-static Energy $\left[\mathrm{E}_{\mathrm{QS}}\right]$ - Dynamic Energy $\left[\mathrm{E}_{\mathrm{DYN}}\right]$

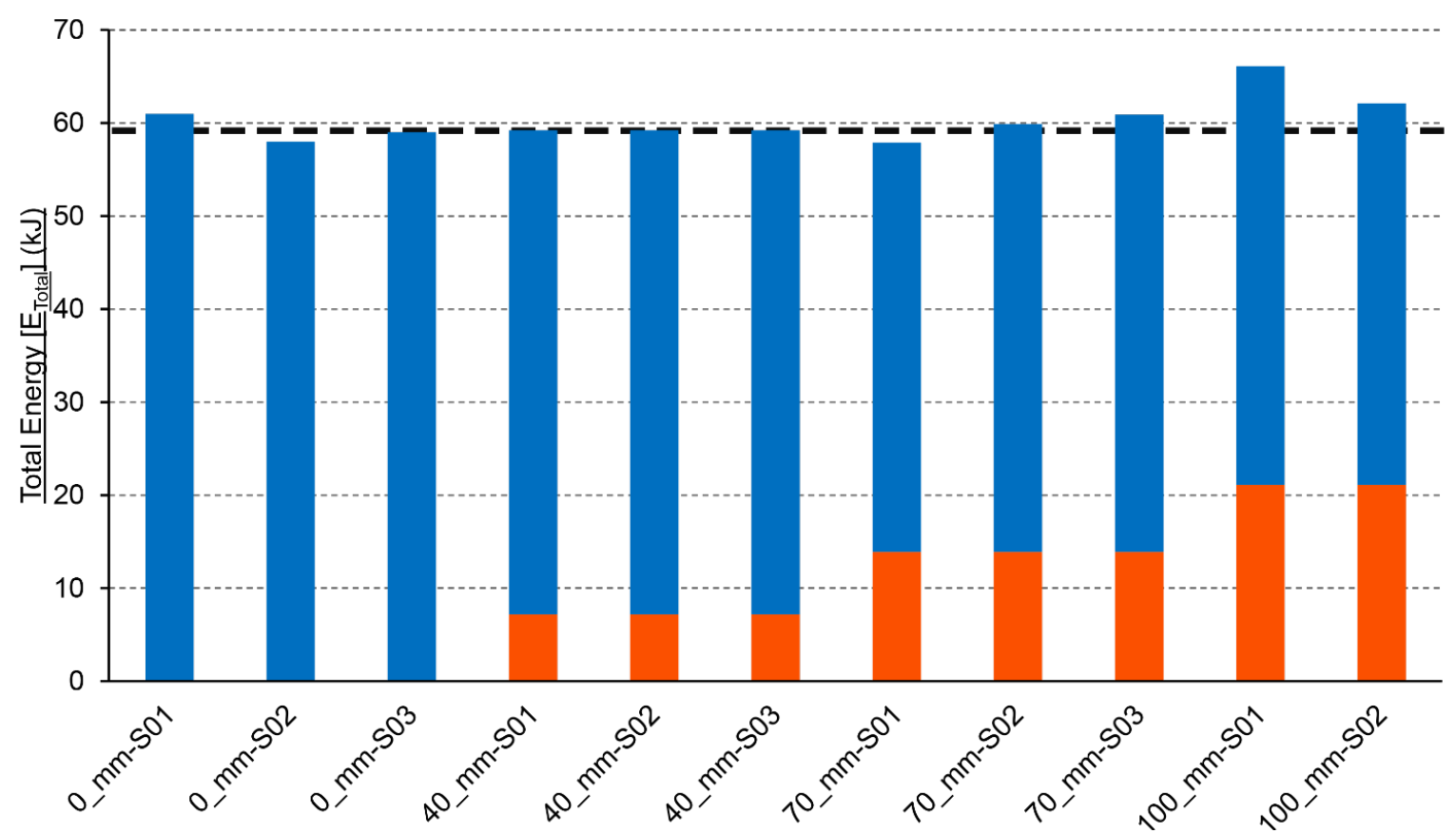

Figure 12 Total energy absorbed [ETotal] by each sample

Therefore, the data suggests a correlation exists between the dynamic energy absorbed during a single impulse to rupture and the total or true capacity of a tendon. While it could be determined as a conservative approach under purely axial elongation, a case may be made that the remaining residual energy within this set of samples could be represented using the following relationship:

$$
E_{D Y N}(x)=E_{D Y N}(0)-E Q S(x)
$$

where:

$$
\begin{array}{ll}
E_{Q S}(X)= & \text { defined as the quasi-static energy (loading rate: } 30 \mathrm{~mm} / \mathrm{min} \text { ). } \\
E_{D Y N}(X)= & \text { the residual single impulse dynamic capacity of the system after elongation of } \mathrm{x} \mathrm{mm} \\
& \text { has occurred. } \\
E_{D Y N}(O)= & \text { the dynamic capacity of the system determined by a single impulse. }
\end{array}
$$

This relationship can be represented as the area under the load-displacement curve of the system throughout the testing cycle. This is graphically represented in Figure 13, where the tendon absorbed $7.2 \mathrm{~kJ}$ of energy during the period of quasi-static elongation to $40 \mathrm{~mm}$ and then an additional $52 \mathrm{~kJ}$ of energy during the dynamic test. This is practically equivalent to $59 \mathrm{~kJ}$ absorbed during the dynamic test of the unstrained tendon; however, the energy is absorbed over a large elongation. 


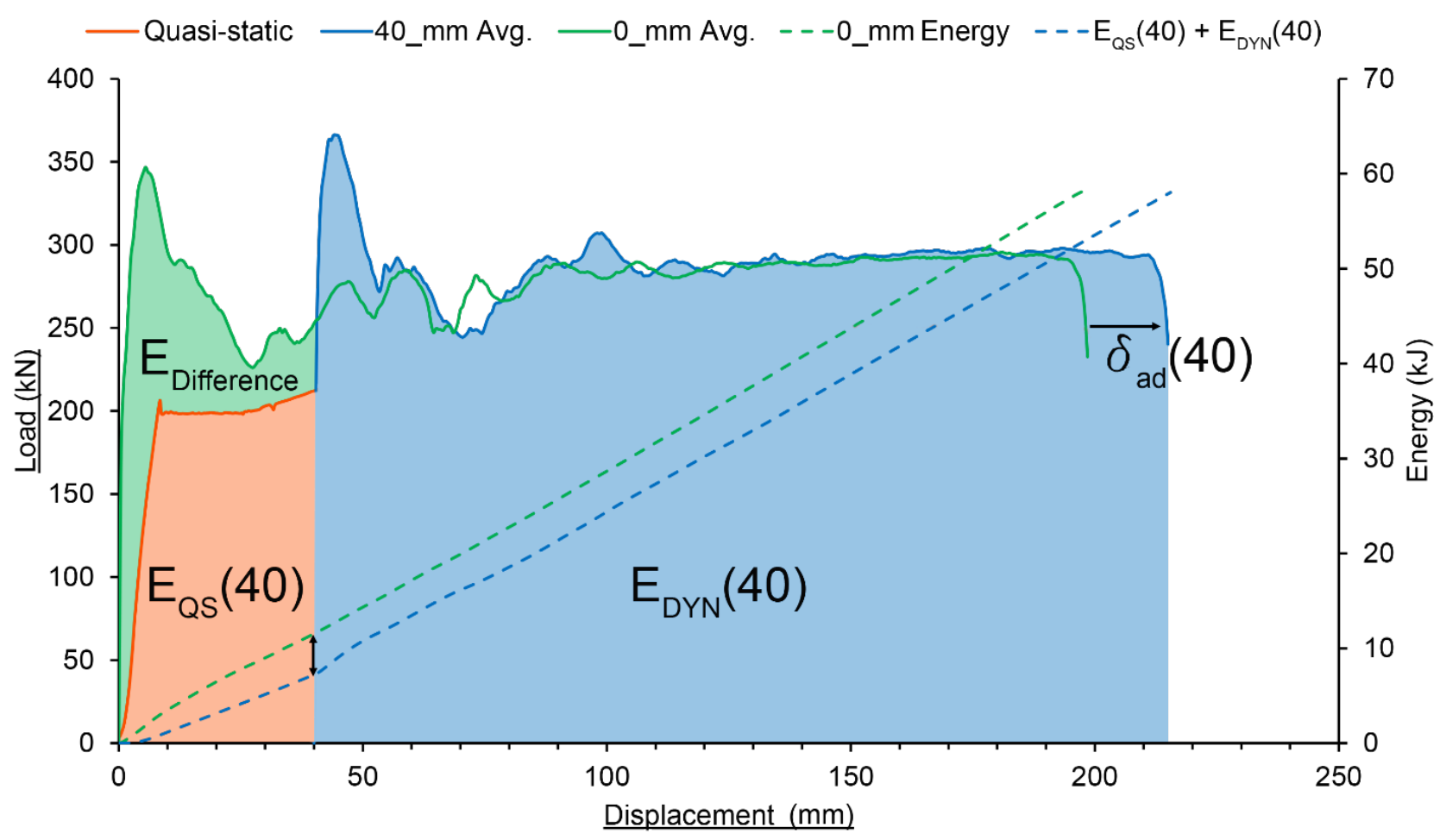

Figure 13 Representation of the total energy absorbed during the testing cycle

\section{Conclusion}

The purpose of this research was to investigate the possible correlation between the quasi-static elongation and the residual dynamic capacity. This dataset indicates a correlation exists between the residual dynamic capacity and the energy absorbed quasi-statically when the tendon is elongated axially. A conservative approach would be to consider the total energy capacity of a tendon as the energy absorbed by a tendon in pristine condition during a single dynamic impulse resulting in the rupture of the tendon. Assuming $\mathrm{E}_{\mathrm{DYN}}(0)$ as the total dynamic capacity, the residual dynamic capacity can be determined as the difference between the total and the energy absorbed during the elongation of the tendon previously experienced.

It is important to remember that the results for this specific support system cannot be extrapolated to other versions of this system and should not be applied to other ground support systems. Although these relationships are currently limited to an axial elongation condition, understanding the behaviour of the materials can assist in understanding the response to a combination of directional loading cases. In applying this data to system design for an underground mine, it is important to account for the effects of shear, corrosion, installation quality and other factors leading to the degradation of the capacity of the support system.

\section{$7 \quad$ Future work}

A number of attributes of the system have been identified for further investigation to better define the relationship between the total energy absorbed by a pre-elongated tendon and the energy absorbed during a single impulse to rupture. These could include some of the following:

- Instrumentation of the quasi-static load frame to enable the quasi-static load curve for each sample. This would increase the dataset size and improve the understanding of the actual quasistatic energy absorbed by the tendon, as a quasi-static energy absorption was calculated from a sample that was loaded at a loading rate of $30 \mathrm{~mm} / \mathrm{min}$ until failure. 
- Investigating the loading cycle with different combinations of quasi-static and dynamic elongation profiles.

- Larger sample sets.

- Further investigation into the increase in total elongation.

- Improving the definition of the ultimate capacity of the tendon.

- Understanding the effects of non-axial elongations, shear and bending.

Additional research will need to be conducted to understand the mechanism resulting in the additional total elongation recorded across the batches of elongated samples when compared with the unelongated control sample set.

\section{References}

ASTM International 2008, Standard Test Methods for Laboratory Determination of Rock Anchor Capacities by Pull and Drop Tests (ASTM D7401-08), ASTM International, West Conshohocken.

Bosman, K, Cawood, M \& Berghorst, A 2018, 'The relationship between the magnitude of input energy per impulse and total absorbed energy', Proceedings of the 3rd International Conference on Rock Dynamics and Applications (RocDyn-3), CRC Press/A.A. Balkema.

Delport, M \& Knox, G 2018, Dynamic Performance of a 20 mm, $2.4 \mathrm{~m}$ PAR1 Resin Bolt when subjected to a $56 \mathrm{~kJ}$ impulse at $5.9 \mathrm{~m} / \mathrm{s}$, New Concept Mining, Johannesberg.

Hadjigeorgiou, J 2016, 'Rock support: degradation and failure', Proceedings of the 8th International Symposium on Ground Support in Mining and Underground Construction, Luleå University of Technology, Luleå, pp. 1-22.

Knox, G \& Berghorst, A 2018, 'Increased agility for the research and development of dynamic roof support products', Proceedings of the 3rd International Conference on Rock Dynamics and Applications (RocDyn-3), CRC Press/A.A. Balkema.

Knox, G, Crompton, B \& Berghorts, A 2018, 'The relationship between the magnitude of impact velocity per impulse and cumulative absorbed energy capacity of a rock bolt', Proceedings of The Fourth Australasian Ground Control in Mining Conference Proceedings, The Australasian Institute of Mining and Metallurgy, Melbourne, pp. 160-169.

Li, CC 2017, Rockbolting: Principles and Applications, Butterworth-Heinemann, Oxford.

Stacey, TR 2012 'Support of excavations subjected to dynamic (rockburst) loading', Proceedings of the 12th International Congress of the International Society of Rock Mechanics, Taylor \& Francis Group, London, pp. 137-145. 